\title{
O trabalho docente dos professores de Educação Física na Rede Municipal de Ensino de Porto Alegre
}

Elisandro Schultz Wittizorecki* Vicente Molina Neto**

Resumo: Este artigo tematiza o trabalho docente dos professores de Educação Física no âmbito da escola pública. Trata-se de uma pesquisa realizada em quatro escolas da Rede Municipal de Ensino de Porto Alegre, onde se investigou como os professores desta rede construíam seu trabalho docente e como articulavam suas ações frente às singularidades do projeto político-administrativo-pedagógico da mesma. Constitui-se em um estudo com orientação predominantemente etnográfica que, elaborado a partir do diálogo entre os referenciais bibliográficos e as interpretações que os professores colaboradores fazem do fenômeno em que estavam inseridos, traz à tona algumas reflexões e contribuições acerca dos dilemas, expectativas e concepções presentes no trabalho docente destes professores.

Palavras-chave: trabalho docente, Educação Física escolar, prática pedagógica.

Este artigo tematiza o trabalho docente dos professores de Educação Física no âmbito da escola pública. Trata-se de uma pesquisa realizada em quatro escolas da Rede Municipal de Ensino de Porto Alegre, onde se investigou como os professores desta rede construíam seu trabalho docente e como articulavam suas ações frente às singularidades do projeto político-administrativo-pedagógico da mesma.

Ao tratar do trabalho docente, o fazemos a partir da perspectiva de professores, preocupados e comprometidos com os conflitos e dificuldades presentes no cotidiano das escolas, entendendo que

* Mestre em Ciências do Movimento Humano e Professor do Curso de Educação Física da Universidade Luterana do Brasil. Doutorando do Programa de PósGraduação em Ciências do Movimento Humano - ESEF/UFRGS.

** Doutor em Ciências da Educação pela Universidad de Barcelona. Professor de Graduação e Pós-Graduação da ESEF/UFRGS.

Movimento, Porto Alegre, v. 11, n. 1, p.47-70, janeiro/abril de 2005 
estes conflitos e dificuldades surgem na medida em que as finalidades educativas propostas pela administração municipal ou as intervenções pedagógicas que se realizam não são suficientemente compreendidas pela comunidade educativa, nem adequadas às peculiaridades culturais e psicológicas dos sujeitos envolvidos, as suas necessidades, capacidades, interesses, valores e expectativas (GOETZ e LECOMPTE, 1988). Ao mesmo tempo, o papel de pesquisadores nos impõe nessa tarefa certo estranhamento cultural e o olhar do fazer científico. A aproximação desses papéis permitiu-nos examinar o tema com maior riqueza e profundidade, simultaneamente com um olhar desde a posição de professor e, com o olhar do fazer científico e sua exigente necessidade de rigor e de reflexão crítica.

Através do convívio e da experiência com os professores e com o ambiente da escola pública, identificamos freqüente-mente avaliações, comentários e reflexões dos docentes a respeito de aspectos relacionados às dificuldades de não disporem de tempo para trocar experiências, avaliar suas práticas mais detidamente e articulá-las às ações de outros professores (pelo fato de possuírem muitas turmas, ministrando aula a estas, uma após a outra); pela sobrecarga de atividades, inclusive em mais de uma escola e por vezes em outros ramos de trabalho; além do cansaço físico e, sobretudo, emocional das jornadas diárias de ensino.

Também são bastante marcantes os discursos em torno das dificuldades em se apropriarem de novos recursos, saberes e tecnologias, uma vez que os cursos de formação inicial possuem limitações em apresentar e explorar esses aspectos, relacionando-os com as próprias peculiaridades sócio-culturais emergentes em cada contexto escolar. Além disso, as possibilidades de formação permanente podem se tornar de elevado custo, horário problemático e pouco relacionados à singularidade de cada realidade escolar.

Por outro lado, é notável como grande parte do coletivo de professores da escola pública - ante as limitações de suas condições de trabalho e a intensificação de suas atividades docentes revela um sentimento de luta, de resistência, criatividade e esperança que os move frente a esses obstáculos. É nessa perspectiva que o professorado constrói suas estratégias de sobrevivência (WOODS, 1995) e resistência diante das dificuldades colocadas pelas condições sociais e materiais de escolarização, como por exemplo, o uso de materiais alternativos, as operações de cooperação, a utilização de recursos/instrumentos próprios nas aulas, os movimentos de organização sindical e reivindicação da classe.

Movimento, Porto Alegre, v. 11, n. 1, p.47-70, janeiro/abril de 2005 
Essa situação se dá paralelamente a um quadro em que a escola pública, em especial, sofre constantes reestruturações administrativas e curriculares, tanto em função das periódicas alterações políticas de gestão, como modo de solucionar problemas como a evasão escolar, o nível de repetência, a escassez de recursos humanos e materiais, as lacunas na formação de professores e o reduzido apoio e participação dos pais na vida escolar. Sem estabelecer um juízo de valor em relação ao peso de um ou outro componente na determinação das atuais condições da escola pública, destacamos os desdobramentos desse quadro no trabalho do professor.

Para além dos impedimentos materiais, comumente encarados como a maior dificuldade do trabalho docente, é importante considerar também as condições sociais da escolarização, como propõem Liston e Zeichner (1997), que se entrelaçam no trabalho do professor. Nessa classe, os autores incluem a expectativa da comunidade em relação ao trabalho docente, as diferenças culturais entre professores e alunos, os mecanismos e disposições da instituição escolar e a forte carga emocional presente na relação pedagógica. Ainda que em sua obra os autores tenham como pano de fundo a discussão destes elementos no processo de formação inicial de professores, sua análise contribui significativamente para o entendimento do trabalho docente à luz das reais e plurais condições do universo escolar.

Pérez Gómez (1998) alerta que os docentes vivem no centro do furacão da inegável situação de crise social, econômica, política e cultural que vive nossa sociedade no atual momento, o que provoca uma sensação de perplexidade aos professores, em virtude da transformação dos fundamentos que orientavam e legitimavam sua prática. Características como a ampliação do papel do professor e a diminuição da responsabilidade familiar sobre a educação dos jovens e crianças; a revolução eletrônica e o intenso crescimento e difusão dos meios de comunicação como instrumentos também pedagógicos, cujos impactos no alunado se dão de forma tão significativa quanto a intervenção dos docentes; a prevalência de valores como o individualismo, a competitividade, a rentabilidade e a obsessão pela eficiência - em que se prioriza a rapidez e o "não perder tempo", em detrimento da reflexão, do pensar, pois representa "perda de tempo" - são elementos que contribuem para a configuração da perplexidade docente frente a uma sociedade em constantes transformações.

Movimento, Porto Alegre, v. 11, n. 1, p.47-70, janeiro/abril de 2005 
Dessa forma, a opção pelo tema desta investigação se deu em meio a esses paradoxos e inquietações, resultantes da experiência e do convívio diários na escola pública: o que significa ser professor? Que expectativas os professores têm em relação ao seu trabalho? Que estratégias constróem para suprir as demandas e exigências que lhe colocam? O exemplo abaixo, trazido por Liston e Zeichner (1997), ilustra concretamente diferentes possibilidades de valoração e interpretação do trabalho docente, pelos próprios professores:

Na maioria das escolas, podemos ver que há docentes que chegam às oito da manhã e saem às três da tarde, enquanto que outros passam a sensação que vivem, respiram e dormem ensinando. Além disso, eles mesmos definem e delimitam seu trabalho de diferentes maneiras. Mas o fatoéque as tarefas educativas não acabam nunca, parecem expandir-se cada vez mais ${ }^{1}$ (p. 119).

Guiados por essas contribuições e com o entendimento de que é possível gerar conhecimento através da investigação educativa da ação cotidiana dos professores, configuramos o problema de pesquisa, cuja pergunta-chave é:

Como os professores de Educação Física constróem seu trabalho docente na Rede Municipal de Ensino de Porto Alegre, e como efetivam e articulam suas ações frente às singularidades do projeto político-administrativopedagógico desta?

\section{Questões para pensar o trabalho docente}

Se por um lado, estas inquietações tiveram papel decisivo para a formulação do problema, as contribuições dos aportes teóricos deste campo do conhecimento constituíram o outro pilar de sustentação da pesquisa. Algumas produções da área da Educação que têm tematizado o trabalho docente, trazem à tona aspectos como a condição do professorado frente à situação de ambigüidade entre o processo de proletarização e profissionalização (FERNÁNDEZ ENGUITA, 1991; JÁEN, 1991), a perda de autonomia e controle de seu trabalho (APPLE e TEITELBAUN, 1991; CONTRERAS DOMINGO, 1997; PÉREZ GÓMEZ, 1998), o processo de feminização do magistério e seus nexos com a proletarização dos professores (HYPOLITO, 1997), as condições sociais de escolarização e a forma-

1 As traduções dessa citação e de outras que aparecem no decorrer do trabalho referentes a essa e outras obras, são de nossa responsabilidade.

Movimento, Porto Alegre, v. 11, n. 1, p.47-70, janeiro/abril de 2005 
ção do professorado (LISTON e ZEICHNER, 1997), as representações que os professores constróem acerca de seu trabalho (SOUZA, 1996) e as questões de gênero, classe e profissionalismo do trabalho de professores em classes populares (COSTA, 1995).

O trabalho docente tem sido marcado pelas transformações sociais que ocorrem no mundo contemporâneo. Os professores defrontam-se cotidianamente com os imprevistos inerentes a sua intervenção, com os limites dos métodos e conteúdos de ensino, com as críticas sobre a defasagem entre o trabalho realizado e os objetivos a serem cumpridos, enfim, com uma série de exigências, expectativas e contingências que atravessam e influenciam seu trabalho. Ao tratar dessas questões, Pérez Gómez (1998) é enfático:

A exigência de renovação permanente para fazer frente às necessidades cambiantes da sociedade, ao incremento vertiginoso do conhecimento científico e cultural, às características peculiares e desconhecidas de cada nova geração de estudantes, aos requerimentos de renovação metodológica derivada do desenvolvimento do conhecimento pedagógico, às demandas da Administração (que impõem modificações políticas e técnicas em cada mudança de governo, legitimadas em maior ou menor grau pela expressão majoritária da população nos processos eleitorais) provoca tanto a tendência positiva à mudança criadora como a freqüente perda de sentido, o desconcerto e a frustração (1998, p. 176).

Nesse sentido, esse mesmo autor caracteriza a escola como uma complexa e fluida encruzilhada de culturas. Seus elementos fundantes seriam a cultura crítica, representada pelos saberes das disciplinas científicas, artísticas e filosóficas construídos e acumulados pela humanidade através do tempo; a cultura social, que consiste no conjunto de valores e princípios hegemônicos de nossa organização social; a cultura acadêmica, refletida na seleção dos conteúdos e disciplinas escolares que constituem o currículo; a cultura institucional, presente nos papéis, normas e rituais próprios da escola como instituição social específica; e a cultura experiencial, representada pelos saberes, habilidades e experiências construídas pelo alunado em seus diferentes intercâmbios com o entorno. Na perspectiva desse autor, são tais condições que definem a natureza, o sentido e a consistência das aprendizagens do alunado na vida escolar.

É nessa trama de determinações, papéis, experiências e influências que os professores se vêem com a necessidade de construir seu trabalho e articular suas ações: ensinar o quê? Por quê? Para quem? Para quê? (COSTA, 1995). São comuns aos docentes as sensações de perplexidade e de incerteza, na medida em que vivem uma tensão entre as exigências de um contexto social móvel, flexí-

Movimento, Porto Alegre, v. 11, n. 1, p.47-70, janeiro/abril de 2005 
vel e incerto e os rituais, convenções e costumes inflexíveis e burocráticos, próprios do sistema escolar (HARGREAVES, 1996).

Portanto, o trabalho docente não ocorre isoladamente no interior das instituições escolares. Pelo contrário, insere-se na complexa teia que caracteriza o nosso cenário social, inter-relacionando-se com uma organização político-econômica definida - a partir da lógica capitalista - e com uma organização social e cultural em franca transformação.

Especialmente em relação aos professores de Educação Física, estas questões tomam uma singularidade especial, dada à própria especificidade da disciplina e da cultura docente de seus professores (MOLINA NETO, 1996). O professorado de Educação Física realiza um trabalho nas escolas, ao mesmo tempo, comum àquele dos outros professores, em função da consonância com os propósitos da instituição escolar; e singular, em função da especifi-cidade dos conhecimentos e das práticas da área. Tal especificidade pode ser facilmente visualizada na natureza dos espaços que os professores de Educação Física utilizam para sua intervenção, na peculiaridade dos materiais e recursos que esses fazem uso, no trato pedagógico com as manifestações da cultura corporal e com o movimento, e mesmo, nas relações que esses docentes estabelecem com outros professores e com o alunado.

Essas características tomam uma particularidade especial no universo das escolas públicas. Em grande parte destas, são notáveis os dilemas e limitações em diversos âmbitos, com que se confrontam os referidos docentes: os precários e reduzidos espaços físicos para as aulas, a quantidade e variedade de recursos materiais, a divergência de representações que professores de Educação Física e alunos fazem desta, a dificuldade de definição da contribuição e legitimidade da disciplina no projeto políticopedagógico da escola, além da tensão que se estabelece, em muitas delas, entre os professores de Educação Física e os setores de supervisão e coordenação pedagógica.

Nessa perspectiva de análise, é importante sublinhar o status inferior da Educação Física em relação às disciplinas representadas como de cunho mais intelectual, oferecidas na escola. Concebida como uma atividade prioritariamente prática, em contra-posição à sobrevalorização da base intelectualista - característica fundamental da escola moderna - seus docentes acabam se situando em condição de desigualdade no coletivo da escola (GÜNTHER, 2000), na medida em que enfrentam o estigma de "trabalho fácil" ou de disciplina de fácil aprovação e pouca exigência.

Movimento, Porto Alegre, v. 11, n. 1, p.47-70, janeiro/abril de 2005 
Essas características representam importantes condições sociais e materiais que, em maior ou menor grau, de acordo com cada contexto escolar, fomentam a criação de estratégias de sobrevivência (WOODS, 1995), de resistência ou acomodação, na construção do trabalho docente dos professores de Educação Física. Essa construção, no entanto, não se dá exclusivamente em função de tais condições. Grande parte do trabalho que o professorado de Educação Física realiza nas escolas, o faz mediado por sua cultura docente, ou seja interagindo com todo um conjunto de crenças, valores, hábitos e formas de fazer construídos histórica e coletivamente por um coletivo de professores, de forma a enfrentar as demandas e pressões similares durante anos, a dar significado e identidade ao trabalho desses docentes e como marco de socialização e iniciação aos novos membros desse coletivo (HARGREAVES, 1996).

Analisando a bibliografia especializada no campo da Educação Física escolar, é bastante comum encontrarmos investigaçoes que enfatizam a prática pedagógica, a função do professor, a formação inicial e a permanente de professores. Nossa decisão de adotar o descritor trabalho docente ocorreu a partir da preocupação em explicitar um entendimento do labor cotidiano dos professores nas escolas, para além do "dar aulas", mas como trabalho que inclui tanto tarefas administrativas como pedagógicas. Nesse sentido, a contribuição de Giroux (1990) é esclarecedora, pois o autor entende que "[...] o trabalho dos docentes como uma forma de tarefa intelectual, em oposição a uma definição do mesmo em termos puramente instrumentais ou técnicos" (p. 176).

Dessa forma, concebemos o trabalho docente como o conjunto de atividades que englobam, para além das aulas que os professores ministram, a participação em reuniões e assembléias administrativas, pedagógicas e com a comunidade escolar; o planejamento, execução e avaliação de sua intervenção educativa; o atendimento aos pais ou responsáveis pelos alunos; a confecção e manutenção de materiais utilizados nas aulas; a organização e participação em atividades e eventos promovidos pela escola; o processo reflexivo que os docentes imprimem a partir de sua prática e o envolvimento e participação nas atividades de formação permanente, tanto promovidas pelo gestor público, quanto naquelas buscadas por iniciativa pessoal.

\section{A organização escolar e o trabalho docente na rede municipal de ensino de Porto Alegre}

O trabalho docente que é foco desta investigação, é aquele desenvolvido pelos professores de Educação Física na Rede Municipal

Movimento, Porto Alegre, v. 11, n. 1, p.47-70, janeiro/abril de 2005 
de Ensino de Porto Alegre. Trata-se de uma rede com uma proposta curricular organizada em ciclos de formação e comprometida com os interesses e necessidades das classes populares. De 1989 a 2004, o município de Porto Alegre foi governado pela Administração Popular. ${ }^{2}$ Na primeira gestão, o projeto educacional inspirou-se em uma proposta construtivista, baseando-se nas teorizações de Jean Piaget, Paulo Freire, Wallon e Emília Ferreiro. Mas é especialmente a partir da segunda gestão, em 1993, que a Secretaria Municipal de Educação - revisando a proposta construtivista - pautou suas ações a partir do princípio da indissociabilidade entre gestão democrática e qualidade de ensino, formando os Conselhos Escolares (órgão máximo das escolas) e investindo nestes, enquanto mentores da discussão de uma nova proposta de gestão nas escolas.

Decorrente da preocupação com a defasagem da escola tradicional em relação às grandes transformacões do final de século XX - escola esta, marcada pela existência de processos de exclusão, evasão, repetência - e pela crítica a esta enquanto transmissora de conhecimentos vazios de significado, em 1994 é desencadeado o projeto Constituinte Escolar. Além disso, buscava-se, e busca-se, construir um projeto de escola fundamentalmente comprometido com as classes populares. A Constituinte Escolar se tratava de um processo coletivo onde, com a participação de todos os segmentos da comunidade escolar (alunos, pais, funcionários e professores), definiram-se os princípios orientadores para a construção de uma escola não excludente, democrática, emancipadora, formadora de sujeitos históricos e autônomos: a Escola Cidadã (AZEVEDO e KRUG, 1999). Um dos princípios da Escola Cidadã ressalta, inclusive, que

o currículo deve buscar uma proposta político-pedagógica progressista, voltada para as classes populares na superação das condições de dominação a que estão submetidas, propiciando uma ação pedagógica, dialética, onde se efetive a construção do conhecimento e a relação entre aprendizagem e desenvolvimento, pela comunidade escolar, tanto da(o) professora(or), da(o) aluna(o), quanto do(a) pai/mãe e da funcionária(o), através de uma atitude interdisciplinar [...] ( Secretaria Municipal de Educação de Porto Alegre, 2000, p. 61).

De forma a contemplar tais orientações, outras propostas foram adotadas, como os Ciclos de Formação e a organização do ensino a partir de Complexos Temáticos. Os Ciclos de Formação ${ }^{3}$ se constitu-

2 Por Administração Popular podemos entender a identidade e a orientação que se imprimiu à gestão política liderada pelo Partido dos Trabalhadores à frente da Prefeitura Municipal de Porto Alegre, incluindo outros partidos de esquerda.

3 Na Rede Municipal de Ensino de Porto Alegre, o Ensino Fundamental está estruturado em três Ciclos de Formação. Cada ciclo tem a duração de três anos, o que amplia para nove anos de escolarização o Ensino Fundamental.

Movimento, Porto Alegre, v. 11, n. 1, p.47-70, janeiro/abril de 2005 
em em uma reorganização dos tempos e espaços da escola, fruto da preocupação com o enfrentamento sério à questão do fracasso escolar. Já os Complexos Temáticos são entendidos como um instrumento orientador do trabalho escolar, pautados numa ação interdisciplinar entre os conteúdos do processo de ensino-aprendizagem e os saberes pré-existentes no contexto cultural da comunidade, investigados a partir da pesquisa sócio-antropológica realizada pelos professores. Dessa forma, o ponto de partida para as definições de ordem pedagógica das diferentes áreas do conhecimento é a realidade, onde enfatiza-se, sobretudo, a construção de conceitos a partir das diversas situações de aprendizagens. Ou seja:

[...] as escolas por Ciclos de Formação da Rede Municipal de Ensino de Porto Alegre, ao trabalharem a organização do ensino a partir de Complexos Temáticos, buscam dar conta de dois aspectos essenciais na construção do currículo: ter vínculo com a realidade e planejar coletivamente as açóes pedagógicas (Secretaria Municipal de Educação de Porto Alegre, 1999, p. 12).

Outro elemento marcante no contexto desta rede de ensino é a garantia aos professores de espaços de planejamento, discussão e reflexão visando qualificar as intervenções na comunidade escolar, além da existência de momentos de formação permanente na forma de reuniões semanais, turnos de formação durante o ano letivo e eventos promovidos fora do âmbito escolar.

É possível notar portanto, todo um discurso de reestruturação e a criação de mecanismos que dêem conta desta, apregoando novas demandas, expectativas e implicações em relação ao trabalho dos professores.

Dessa forma, procuramos discutir, no decorrer do trabalho, como essas diferentes características da Rede Municipal de Ensino de Porto Alegre influem e se concretizam no trabalho específico dos professores de Educação Física. Como estes, frente à tradição coletiva da área e frente a sua cultura docente (MOLINA NETO, 1996) específica percebem essas condições peculiares da Rede Municipal de Ensino e como estas perpassam no seu trabalho docente? A seguir são apresentadas as opções metodológicas que trilhamos para responder essas questões.

\section{Decisões metodológicas}

A opção pela investigação de corte qualitativo neste trabalho se dá em função do entendimento de que é nessa perspectiva que enfatiza-se a compreensão da singularidade e a contextualidade de fatos e eventos (SILVA, 1996), preocupando-se fundamentalmente com os sentidos que as pessoas dão às coisas e as suas ações.

Movimento, Porto Alegre, v. 11, n. 1, p.47-70, janeiro/abril de 2005 
Este estudo também está norteado por uma orientação predominantemente etnográfica (GOETZ e LECOMPTE, 1988; MOLINA NETO, 1996). Tal escolha é coerente com o propósito da investigação e se justifica na medida em que permite a reconstrução das vozes dos sujeitos envolvidos no problema de pesquisa, além de resgatar a interpretação que fazem do fenômeno no qual estão inseridos. Woods (1995) contribui de forma bastante esclarecedora acerca do propósito da etnografia, colocando que ela

se interessa pelo que as pessoas fazem, como se comportam, como interagem. Se propõe descobrir suas crenças, valores, perspectivas, motivações eomodo em que tudo isso se desenvolve ou muda com o tempo, ou de uma situação a outra. Trata de fazer tudo isso, desde dentro do grupo e desde dentro da perspectiva dos membros do grupo. O que importa são seus significados e interpretações (p. 18).

Portanto, não é propósito estabelecer generalizações universais a partir das informações e interpretações resultantes, quer seja para outras redes de ensino, outros centros escolares ou outros coletivos docentes, mas prioritariamente apoiar os processos de reflexão e crítica para tratar de melhorar a qualidade dos processos de ensino-aprendizagem (GOETZ e LECOMPTE, 1988). Dessa forma, entender o trabalho docente a partir da perspectiva dos professores, sem o cunho prescritivo e moralista é o modo mais adequado a uma investigação que pretende suscitar reflexões e contribuições pedagógicas acerca da intervenção cotidiana dos docentes no interior das escolas.

Para tanto, é necessário que os procedimentos adotados para a obtenção de informações sejam coerentes com o delineamento da pesquisa e com o problema de investigação. Nesse sentido, foram utilizados instrumentos como a observação, o diário de campo, a entrevista e a análise documental em um trabalho de campo que durou dez meses. Os participantes dessa investigação são professores de Educação Física de quatro escolas da Rede Municipal de Ensino de Porto Alegre, constituindo um grupo de doze colaboradores. Os critérios estabelecidos para a escolha dos professores levam em consideração a preocupação de obter um grupo com maior diversidade de perfis, de graus de experiência e de envolvimento com o âmbito municipal de ensino e com a comunidade escolar em que estão inseridos. Não houve a preocupação de formar uma amostra estatisticamente significativa, uma vez que a pesquisa com o delineamento que apresentamos enfoca a representatividade tipológica dos colaboradores (MOLINA NETO, 1999) e sua vinculação ao problema de pesquisa.

Movimento, Porto Alegre, v. 11, n. 1, p.47-70, janeiro/abril de 2005 
A pesquisa tem início desde os primeiros contatos com o fenômeno estudado. A negociação de acesso e a coleta da informação não são fases distintas do processo investigador. Portanto, desde a tensão e a insegurança da entrada nas escolas, as primeiras conversas com os professores, a desconfiança e a curiosidade destes até as expressões não-verbais resultantes desses contatos, são elementos importantes de um processo que se aprofunda permanentemente em diferentes níveis (WOODS, 1995).

A idéia que melhor explica a estratégia inicial de acesso ao campo de pesquisa é, partilhando da proposição de Rodríguez Gómez et al. (1996), o "vagabundeio". . Ou seja, foi realizado um progressivo reconhecimento do marco físico e social das escolas em que se realizaria a pesquisa e uma aproximação às pessoas que nela convivem. Ou seja, circular pela escola, conversar com os professores e alunos, observar situações, pessoas e comportamentos indistintamente, eram atitudes tomadas de modo a ambientar-se com o local, para partilhar da cultura do grupo estudado, enfim, até tornar-se parte do contexto e desde ele, reconstruir o sistema de representações e significados que tal grupo partilha.

Após essa fase, foram realizadas observações de forma mais focalizada. Após o período mais intenso de observações, a realização das entrevistas com os colaboradores se tornou foco do processo, diminuindo a freqüência das visitas às escolas. Isso porque o trabalho de transcrição das entrevistas exige um considerável dispêndio de tempo e atenção em sua execução. Em seguida à realização destas, as entrevistas foram transcritas e submetidas à apreciação dos colaboradores entrevistados, de modo a receber seu aval para utilização. Esse processo de audição e transcrição mostrou-se extremamente importante à análise das informaçốes, pois vários dados e questões, que no momento da realização da entrevista passam despercebidos, puderam ser retomados e tratados já em um primeiro nível de análise.

Depois de recolher as informações provenientes das observações, das entrevistas, das notas do diário de campo e da análise de documentos, teve início o processo de análise e tratamento das informações, de modo mais exclusivo. Isso porque, no delineamento deste estudo, esse processo não se realiza de forma estanque e linear ao final da investigação, mas paralelo à coleta de informações. 4 Ainda que a palavra "vagabundeio" consista numa expressão grosseira na Língua
Portuguesa, resolvi utilizá-la de forma a manter uma fidedignidade ao seu corres-
pondente "vagabundeo" na Língua Espanhola. Evidentemente, utilizo-a na acepção
de uma estratégia metodológica de aproximação e permanência nos locais em que se vai realizar o trabalho de campo.

Movimento, Porto Alegre, v. 11, n. 1, p.47-70, janeiro/abril de 2005 
A partir de repetidas leituras das entrevistas, foram identificadas as unidades de significado, ou seja, foram destacados os elementos mais relevantes e significativos presentes nas diferentes falas dos colaboradores. Resultaram desse processo 317 unidades de significado, que foram agrupadas por proximidade temática, levando em conta as informações obtidas no diário de campo, nos documentos analisados e nas observações realizadas. Desse modo, foi iniciada a construção das categorias de análise.

A pesquisa de orientação etnográfica segue, assim como estratégias, instrumentos e propósitos singulares, uma forma de validez também própria. Rodríguez Gómez et al. (1996) sugerem como indicativos de validez de uma pesquisa dessa natureza a presença prolongada no campo, o intercâmbio de opiniões com outros investigadores e a triangulação. Dessa forma, construí a validez em três diferentes níveis.

O primeiro nível de validez foi construído no momento em que foi entregue a transcrição da entrevista aos respectivos colaboradores, para que pudessem ler e, caso avaliassem necessário, incluir modificações no relato. O segundo nível de validez foi construído através da triangulação entre as informações que recolhemos no trabalho de campo, as contribuições dos referenciais bibliográficos estudados e os documentos consultados. Segundo Pérez Gómez (1998), o exercício rigoroso da triangulação oferece uma base rica para oferecer validez interna à investigação, na medida em que o pesquisador estabelece o contraste de suas diferentes interpretações subjetivas com os fatos registrados e com as interpretações de outros indivíduos e grupos internos e externos aos mesmos acontecimentos. O terceiro nível de validez ocorreu através da submissão da redação final da investigação à apreciação de dois professores de Educação Física que não participaram da investigação. Constituem dois professores com experiência na área da Educação Física escolar e que atuam com o Ensino Fundamental no âmbito da Rede Municipal de Ensino de Porto Alegre. Neste nível, foi avaliado, junto a outros professores com as mesmas características do grupo investigado, o grau de validez das interpretações construídas e sua correspondência à realidade.

\section{O trabalho docente no cotidiano das escolas estudadas}

O trabalho docente desses professores está marcado pelas pautas da organização escolar e pelas condições específicas de suas escolas, que no caso deste estudo, fazem parte de uma rede de ensino com características bastante singulares e que vem atravessando

Movimento, Porto Alegre, v. 11, n. 1, p.47-70, janeiro/abril de 2005 
um processo de reestruturação curricular e implementação de novas propostas pedagógicas. Fato que torna a escola espaço de construção de uma caminhada pedagógica, muitas vezes inédita e complexa para os professores.

Na construção cotidiana do trabalho docente do professorado de Educação Física, quatro elementos são fundamentais: os dilemas e inquietações com que esses docentes se defrontam em sua labuta diária, as estratégias e saberes construídos de forma a dar conta das demandas e exigências que tais dilemas e inquietações representam, a forma como concebem e docência e as transformações no seu papel enquanto professores.

Desse modo, ao construírem seu trabalho, em uma relação dialética, também se constróem e se forjam professores, afirmando e reelaborando suas convicções pessoais e pedagógicas, além de seus significados e concepções de docência, que por sua vez pautam e fundamentam as decisões na construção de seu trabalho.

Um elemento importante na construção do trabalho docente desses professores é a aprendizagem construída a partir da experiência ao longo dos anos no universo escolar. Como aponta Molina Neto (1998), o "aprender fazendo" constitui uma das marcas da cultura docente desses professores. Na Rede Municipal de Ensino de Porto Alegre, esse "aprender fazendo" toma um especial peso, dada as reestruturações propostas em seu projeto político-administrativo-pedagógico, que coloca os professores frente a tarefas e atribuições novas, complexas e, muitas vezes, inéditas.

Durante o contato com os professores colaboradores, onde relatavam as experiências de trabalhos anteriores e atuais, ficou muito nítido o senso de observação e a "capacidade de leitura" que os docentes elaboram acerca de elementos decisivos na construção de seu trabalho: o perfil dos alunos, as características sócio-culturais da comunidade em que atuam e as mudanças em suas convicções pedagógicas ao longo de sua trajetória histórico-laboral. Essa capacidade reflete o estágio de amadurecimento pessoal e profissional possibilitado pelas experiências e reflexões de sua intervenção cotidiana na escola, pelas contribuições das leituras e das atividades de formação permanente que realizam e pelo desenvolvimento de algumas competências, como o senso de observação ampla e, ao mesmo tempo, focalizada, o senso crítico e atitude de escuta frente aos sujeitos com que interage. Nessa perspectiva, a fala de Vera ${ }^{5}$ é bastante elucidativa:

5 Em todo o texto os nomes dos professores colaboradores foram substituídos por nomes fictícios de modo a preservar a sua identidade.

Movimento, Porto Alegre, v. 11, n. 1, p.47-70, janeiro/abril de 2005 
Eu comeceiem 1998, daquelejeito, semexperiêncianenhuma, commuitas fantasias, trazia material, balóezinhos, enada dava certo, porque as crianças estouravam tudo quanto era balão, antes de começar a atividade. Eaos poucos, naquele ano, aos poucos eu fui pegandoojeito da coisa, jáno segundoe terceiroano, eu já conseguideslanchar maisnesse sentidoassim, de veroquequeeles queriam, embora tivesseoplanejamento, eu soubesse o que tinha que trabalhar, mas nem todas as crianças estavam a fim. Então, a gente adquire, claro, aprendizado aí com a prática, enfim diariamente. (professora de Educação Física do II Ciclo, 9 anos de experiência docente)

As formas de fazer de seus colegas e as características históricas da Educação Física em cada centro escolar representam, para alguns professores, importantes elementos que pautam o trabalho docente desse coletivo. Evidentemente que os professores que atuam há mais tempo nessa rede e que passaram pela vivência de várias propostas, apresentam uma outra plataforma de concepções, crenças e experiências para a construção de seu trabalho docente. Ressaltando a importância de compreender o contexto em que atuam, Cristina pondera:

Trabalhando com classes populares, tudo que tu aprendeu dentro da faculdade aqui tu não... a única coisa que tu usa assim, vamos dizer, claro, o desporto, o futebol se joga com o pé e tem as regras dele, claro; mas, às vezes, até tu tem que modificar um pouco dessas regras, para poder adequar ao nosso aluno. Então assim tu tem que adequar aquilo que tu aprendeu a tua realidade. Porque a tua realidadeénão ter quadra, énão ter bola boa, étunão ter lugar coberto, étu ter que dar uma aula de Educação Física dentro de uma sala de aula com cadeira e com mesa, porque tem que ficar ali. Então assim, é adequar aquilo que tu aprendeu na faculdade para lidar com esse pessoal, que é muito difícil, é muito difícil. (professora de Educação Física do II e III Ciclos, 25 anos de experiência docente)

Seu entendimento encontra-se muito próximo à perspectiva de Pérez Gómez (1998), quando apresenta a idéia de compreensão situacional. Esse autor argumenta que a compreensão situacional consiste em um processo de reconstrução da própria experiência e do próprio pensamento, que o docente realiza ao indagar as condições materiais, sociais, políticas e pessoais que constituem a situação educativa. Durante a investigação, foi possível acompanhar um intenso processo de "tomada de consciência" que marcava esses professores ao analisarem o contexto em que atuam, e que propiciava a estes pensar e criar estratégias e alternativas para a construção de seu trabalho.

Por outro lado, esse processo reflexivo nem sempre encontra condições ideais para ocorrer. Durante as observações realizadas, freqüentemente os professores viram-se frente a situações inusitadas que os colocavam na iminência de uma pronta tomada de decisão. Esse é um traço característico do trabalho docente dos 
professores de Educação Física nas escolas estudadas: as contingências enfrentadas no seu cotidiano e a necessidade de respostas imediatas a estas, ante o caráter vivo, incerto e dinâmico desse universo escolar.

Tais situações, aliadas ao grande volume de trabalho dos professores - que dificulta oportunidades de reflexão coletiva e, muitas vezes, conduzem ao isolamento docente - levam os docentes a adotarem outros mecanismos que lhe ofereçam respostas rápidas a sua necessidade imediata de ação. Vera ilustra essa situação:

Tá todo mundo sempre a mil, a direção sempre a mil, tu não consegue, eu não consigo chegar lá e conversar sobre um aspecto lá das minhas aulas, não consigo. Até de como proceder, de determinados casos, aí o que que acontece? A gente vai tocando, vai fazendo conforme a intuição vai mandando muitas vezes, e justamente porque é muito corrido, todo mundo tá sempre correndo.

Durante o período de permanência nas escolas, foi possível aprofundar a compreensão do trabalho docente desses professores na relação com demanda da proposta da Escola Cidadã. Imersos em uma rede de ensino que redimensiona o sentido da avaliação, da aprovação e reprovação para diferentes formas de progressão; que insere outras formas de avaliação como os relatórios descritivos, que enfatiza a prática pedagógica pautada na formação de conceitos a partir de situações contextualizadas e de problemas da realidade, ao invés da transmissão de conteúdos; que procura aproximar as diversas disciplinas através do planejamento coletivo dos professores que trabalham com determinado ano-ciclo; que se propõe tratar pedagogicamente, valores, habilidades e sentimentos, ao invés da exclusividade no trato com o conhecimento e que investe em estratégias de formação permanente dos docentes; o professorado de Educação Física constrói seu trabalho de forma a aproximar-se dos pressupostos que pautam a Escola Cidadã. No entanto, essa aproximação e afinação com a proposta da Escola Cidadã não tem ocorrido de modo linear; trata-se sobretudo, de um processo de constante construção pelos professores vistas as inovações que tal projeto escolar propõe - marcado por conquistas e dificuldades, resistências e acomodações. Nesse sentido, Mara apresenta seu ponto de vista:

Eu acho que é um processo em andamento. Eu acho que ninguém tá dando conta de tudo. As vezes eu acho difícil, ainda tenho dificuldade de trabalhar com o complexo temático, de fazer uma aproximação, dependendo do complexo fica difícil uma aproximação. Não poder estar planejando com todos e não poder estar em sala de aula um pouco, dificulta. (professora de Educação Física do I e II Ciclos, 12 anos de experiência docente)

Movimento, Porto Alegre, v. 11, n. 1, p.47-70, janeiro/abril de 2005 
É possível pensar, então, que na construção do trabalho docente dos professores de Educação Física nas escolas estudadas, o esforço por adequar o trabalho desses às características do contexto em que atuam e às orientações que recebem da proposta que rege a rede municipal, caracteriza a permanente e diária criação e reconstrução de sua intervenção nos centros escolares. Nesse processo, os professores interagem com as limitações e possibilidades de seu trabalho, marcadas fundamentalmente pelas expectativas, inquietações e dilemas com que se deparam nas escolas e pelas estratégias e saberes que constróem, de modo a darem conta dessas. Tais sentimentos resultam tanto da reflexão sobre a própria prática, como das condições materiais concretas em que constróem seu trabalho.

Para o melhor entendimento das interpretações apresentadas, cabe destacar que os dilemas mencionados podem ser traduzidos nos desafios que os professores percebem em seu cotidiano. Quanto às inquietações, podem ser compreendidas como as preocupações, as provocações que mobilizam os professores na construção de suas estratégias e saberes.

Para Carlos, uma das preocupações centrais em seu trabalho é:

Superar ummodelo tradicional de ensino, superar uma prática tradicional deensino, que seria uma tendência nossa a seguir aquele modelo da esportivização. Me parece, que, claro, émais tranqüilo, émais fácil, tu lidar com a questão esportiva, principalmentecomoensino do futebol, comoensino do voleibol, porquenossas práticas, nossa formação direcionou muito para isso, vejo a maior dificuldade, justamente, éconseguir fazer com que os alunos vivenciem situações lúdicas, dentro da aula de Educação Física, que consigam fazer mudanças de comportamento em nível afetivo. (professor de Educação Física do II e III Ciclos, 20 anos de experiência docente)

Essa fala retrata igualmente o pensamento dos demais colaboradores, na medida em que há uma nítida preocupação dos professores em construir uma prática pedagógica alicerçada na produção de aprendizagens significativas, e portanto, de redimensionar tanto o conhecimento de que trata a própria disciplina, como o trabalho que realizam.

Um dos empecilhos para essa mudança consiste na representação de Educação Física que o alunado constrói. Os significados pessoais atribuídos à aula de Educação Física, as experiências anteriores com outros professores e em outras escolas, além da influência de outros aparatos, espaços e instituições que tratam das manifestações da cultura corporal, constituem elementos que perpassam o trabalho docente dos professores de Educação Física diariamente. Grande parte do trabalho que realizam os professo-

Movimento, Porto Alegre, v. 11, n. 1, p.47-70, janeiro/abril de 2005 
res, o fazem influenciados pelos processos formativos - marcados pela tradição esportiva da área. Embora não seja a pretensão desta investigação abordar centralmente e aprofundar a questão da formação de professores, é fundamental, pelo menos nesse momento, analisar como a incorporação e cristalização de determinadas formas de fazer, hábitos, crenças e mitos pautam a construção do trabalho dos professores, através do peso que assume os processos de formação, sobretudo a inicial, e a trajetória histórica e profissional dos docentes.

Outro aspecto que permeia o trabalho docente dos professores de Educação Física é a natureza das reformas educativas colocadas que, ao apresentar uma importante remodelação de sua prática pedagógica e no sentido de seu trabalho, provoca algumas condições, como o de isolamento ou de "estar perdido". Essa crença de "estar perdido" parece refletir o próprio caráter inovador das reestruturações apontadas, já que em última instância, cabe aos professores a tarefa de transformar as macro-orientações de tais reformas em práticas concretas no cotidiano da escola e em seu trabalho. Essa falta de respaldo institucional representa uma séria lacuna nas ações desenvolvidas pela Secretaria Municipal de Educação, uma vez que expõe os professores a um contexto de isolamento e a uma sensação de que compete exclusivamente a eles tomar as iniciativas e levar a frente tal projeto educacional.

Estas condições têm dificultado sobremaneira a articulação dos professores entre si e destes com outros setores da escola, na construção e reflexão compartida com seus pares acerca de seu trabalho docente. Trata-se de condições estruturais que pautam a escola e o trabalho de seus professores no marco de uma sociedade capitalista, ocasionando fenômenos visíveis como a intensificação do trabalho e o isolamento dos trabalhadores.

A questão da forte carga emocional presente no cotidiano dos professores constituiu um elemento de destaque, observado no trabalho de campo. A maioria dos professores afirmou o impacto desta questão na construção de seu trabalho docente e narrou situações que lhe provocam inquietações, dúvidas, angústias. Passam, enfim, por um processo de repensar e reestruturar suas convicções e ações. Mara declara:

E a profissão da gente parece que tá entrando meio que por um caminho assim. A gente está tendo que ter um certo trabalho de dividir um pouco, porque assim, a solicitação emocional eu acho muito forte, a gente passa por coisas assim perigosas, situações de risco, situações de ameaça. Saímos outro dia e ficamos sabendo que no dia seguinte que, tipo assim, meia hora depois que a gente tinha 
saído, teve um tiroteio com morte. Então assim, tem que trabalhar um pouquinho coisas que há um tempo atrás não era necessário.

É possível perceber o contexto de tensão e de preocupações em que os professores realizam seu trabalho. Essas questões são dificilmente abordadas na formação inicial e fica candente a indagação de que até que ponto o conteúdo das estratégias de formação permanente promovidas pela administração municipal têm conseguido dar conta das mesmas. Esses temores e angústias correm o risco de serem banalizados pelos docentes - incorporando-os como uma "naturalidade" em seu trabalho - em função de sua intensa exposição a tais condições e o limitado alcance do que as estratégias de formação permanente têm proposto nessa esfera de dificuldades.

Outra questão fundamental na construção do trabalho docente deste coletivo de professores acompanhada em todas as escolas é a permanente busca em estabelecer combinações com os alunos. Essa iniciativa procura concretizar um importante elemento na organização da Escola Cidadã: os princípios de convivência. Através dessa dinâmica, os professores procuram firmar tratos e mediar os diferentes significados que o alunado atribui à Educação Física e à intervenção do professor, de modo a criar melhores condições para a construção de seu trabalho. Nessa perspectiva, sublinhamos a importância do desenvolvimento de competências relacionais pelo professor: desenvolver a compreensão situacional (PÉREZ GÓMEZ, 1998) e as habilidades de argumentar, de negociar e mediar momentos de tensões e divergências podem se mostrar tão necessárias quanto o domínio de um repertório de atividades na construção do trabalho docente.

As informações acumuladas durante o trabalho de campo permitem pensar que a preocupação central dos professores deslocase da prioridade dos conteúdos - predominante em determinados modelos pedagógicos - para a construção de um vínculo sólido com o aluno. É este vínculo que permitirá ao trabalho do professor incursionar em outros conteúdos e trazer aprendizagens significativas para os alunos.

As estratégias e saberes que os professores constróem na configuração de seu trabalho constituem não só mecanismos que criam para dar conta das demandas e desafios com que se deparam. Fazem parte de um processo mais amplo que passa pela reelaboração das convicções pessoais e pedagógicas dos professores, ou seja, passa pelo permanente e diário processo de reflexão sobre seu papel e sobre suas atribuições.

Movimento, Porto Alegre, v. 11, n. 1, p.47-70, janeiro/abril de 2005 
O processo de redefinição dos papéis dos professores reflete por um lado, a assunção pelos professores, de uma série de expectativas da comunidade e de si próprios em relação à educação escolar, e por outro, um processo mais amplo de transformação social, caracterizado pela redefinição do papel de diversas instituições (família, escola, Estado) e pela revisão de conceitos, princípios e práticas, tidos até então como legítimos nestas.

Esse processo de redefinição de seu papel que os professores indicam refere-se, sobretudo, a uma ampliação de suas atribuições, comparadas ao que, tradicionalmente, pensavam constituir a função docente: planejar, executar e avaliar o ensino-aprendizagem dos alunos. A própria intensificação e a saturação de tarefas do trabalho docente, contribuem para essa redefinição, na medida em que propiciam uma sobreposição de problemas e necessidades que o professor precisa dar conta em sua intervenção, de modo rápido e imediato. Essa sobreposição e confusão de papéis ocorre, no ponto de vista dos colaboradores, na maior parte, com a instituição familiar.

Para Tedesco (apud PÉREZ GÓMEZ, 1998), esses acontecimentos refletem parte de um processo mais complexo, onde tem ocorrido uma mudança nos padrões de socialização e do papel da escola e dos professores. O autor sugere que tem ocorrido uma inversão de funções: desde a estrutura familiar ao sistema educativo, de modo que este último começa a atender com maior intensidade as dimensões afetivas, emotivas e psicológicas do indivíduo em formação (socialização primária), cuja competência primordial caberia à família, enquanto que a família tem se constituído apenas em locus de socialização secundária, isto é, tratando de informações instrumentais e culturais, cuja competência essencial vinha cabendo à instituição escolar. Fica clara a necessidade de respaldo institucional de forma a amparar o professor em um contexto tão conflitivo, onde as dificuldades de aprendizagem se mesclam com outros problemas (relacionais, familiares, emocionais, de saúde), configurando o trabalho docente para além da esfera pedagógico-escolar.

Entendendo a escola não como um marco de consenso, mas como um cenário social onde se apresentam interesses e contradições tão complexos e intensos como na própria sociedade, e considerando o contexto de conflito social em que atuam os professores colaboradores, é possível compreender que o trabalho desses docentes está permeado pelo constante e inevitável repensar de seu sentido, de sua natureza e de suas incumbências, exigindo dos professores, desse modo, para além de competências técnicas

Movimento, Porto Alegre, v. 1 1, n. 1, p.47-70, janeiro/abril de 2005 
e instrumentais, outras, como a reflexão sobre a própria prática, o desenvolvimento da tolerância frente as limitações pessoais e institucionais e a articulação com as demais parcelas da comunidade escolar.

\section{Considerações finais}

Através das informações obtidas no trabalho de campo, fundamentalmente nas observações realizadas, nas notas do diário de campo e nos relatos das entrevistas, desenvolvemos uma compreensão ampliada do trabalho que realizam os professores de Educação Física nas escolas estudadas, cujas determinações e implicações partem e atingem, simultaneamente, o contexto em que se inserem. A construção do trabalho docente dos professores investigados configura-se na articulação entre as marcas do contexto (comunidade, escola e o entorno desta) em que atuam, pela pautas da organização escolar e curricular da rede em que trabalham e pelos significados que atribuem à docência que exercem.

Ao acompanhar a intervenção diária dos professores nas escolas e ao ouvir seus relatos, foi possível compreender o processo complexo que envolve seu trabalho docente: suas ações transcendem o ato de ministrar aulas, havendo uma expectativa que abarque também outros campos que não só a educação escolar. Certamente, tal demanda ocorre em função do perfil da comunidade que o professorado atende, cujas necessidades não se limitam às questões educacionais, mas fundamentalmente, englobam a premente urgência de condições sociais mais dignas e humanas de vida. Esse envolvimento e comprometimento retrata a forma como os colaboradores concebem a docência e as próprias expectativas que têm em relação ao seu trabalho. Ao mesmo tempo em que apontam uma redefinição de seus papéis e atribuições, assumem estes, que por sua vez pautam o trabalho docente que constróem. Ainda é importante ressaltar que a própria concepção de docência e a redefinição de papéis refletem o caráter, de certa forma, transformador e inovador do projeto político-administrativo-pedagógico que a Rede Municipal de Ensino de Porto Alegre vem colocando aos professores. Portanto, pensar o trabalho docente dos professores de Educação Física remete à necessidade de considerar as condições curriculares, pedagógicas e organizacionais em que estão inseridos.

Os dilemas e inquietações com que os docentes se confrontam cotidianamente nas escolas derivadas das características do cenário social em que estão inseridos, das contingências ineren-

Movimento, Porto Alegre, v. 11, n. 1, p.47-70, janeiro/abril de 2005 
tes ao ato educativo e do caráter dinâmico e cambiante do trabalhar com outras pessoas, constituem a base necessária para que estes trabalhadores construam diariamente uma série de estratégias (como as operações de cooperação e aliança) e saberes (como a "capacidade de leitura" da realidade e a tolerância às adversidades), para lidarem não só com as demandas e necessidades que estas condições lhes colocam, como também, com as incertezas e desafios que os pressupostos da Escola Cidadã lhe exigem.

Este texto traz sua contribuição no apoio aos processos de formação inicial e permanente dos professores de Educação Física, na medida em que retrata as circunstâncias em que estes docentes constróem seu trabalho nas escolas. Considerar as expectativas, as contradições e as condições estruturais em que os professores realizam seu trabalho, através da perspectiva da escuta destes, torna-se importante e necessário a um entendimento de formação que busca não só autorizar legalmente uma pessoa para a docência, mas capacitá-lo efetivamente para a compreensão do caráter dinâmico e contigente do trabalho docente, para a reflexão de sua própria intervenção e a reconstrução consciente desta

Nesse sentido, apresentar muitas descrições e falas dos colaboradores propicia ao leitor outras tantas possíveis interpretações acerca do trabalho docente do coletivo de professores investigado. Dar vez e voz aos trabalhadores que constróem e sustentam o processo educativo nas escolas, constitui um rico caminho para entender as limitações e possibilidades do trabalho docente, na perspectiva de melhor refleti-las e reconstruí-las.

Movimento, Porto Alegre, v. 11, n. 1, p.47-70, janeiro/abril de 2005 
The teaching work of the teachers of Physical Education in the Municipal Net of Education of Porto Alegre Abstract: This article talks about the teaching work of the teachers of Physical Education in the scope of the public school. One is about a research carried out in four schools of the Municipal Net of Education of Porto Alegre, where if it investigated as the teachers of this net building its teaching work and as they articulated its action front to the politician-administrative-pedagogical project of the same one. One consists in a study with predominantly ethnography orientation that, from the dialogue between the bibliographical allusions and the meanings that the collaborating teachers make of the phenomenon where they were inserted, show up some reflections and contributions concerning the challenges, expectations and conceptions in the teaching work of these teachers.

Keywords: teaching work, School Physical Education, pedagogic practice.

El trabajo docente de los professores de Educación Físi-
ca en la Red Municipal de Enseñanza de Porto Alegre
Resumen: Este artículo trata del trabajo docente de los
profesores de Educación Física en el ámbito de la escuela
pública. Es una investigación realizada en cuatro escuelas
de la Red Municipal de Enseñanza de Porto Alegre, don-
de se investigó como los profesores de esta red construían
su trabajo docente y como articulaban sus acciones fren-
te al proyecto político-administrativo-pedagógico de la
administración municipal. Se constituye en un estudio
con orientación predominantemente etnográfica que, la
partir del diálogo entre la bibliografía y las interpretaciones
que los profesores colaboradores hacen del fenómeno
en que estaban inmersos, propone algunas reflexiones y
contribuciones sobre los dilemas, expectativas y
concepciones presentes en el trabajo docente de estos
profesores.
Palabras-clave: trabajo docente, Educación Fisica es-
colar, practica pedagogica.




\section{Referências}

APPLE, Michael; TEITELBAUN, Keneth. Está o professorado perdendo o controle de suas qualificações e do currículo? In: Teoria e Educação. Porto Alegre, n. 4,1991, p. $62-73$.

AZEVEDO, José Clóvis; KRUG, Andréa. Século XXI: qual conhecimento? qual currículo? In: SILVA, Luiz Heron da. Século XXI: qual conhecimento? qual currículo? Petrópolis: Vozes, 1999, p. 7 - 17.

CONTRERAS DOMINGO, Jose. La autonomía del profesorado. Madrid: Morata, 1997

COSTA, Marisa Cristina Vorraber. Trabalho docente e profissionalismo. Porto Alegre: Sulina, 1995

FERNÁNDEZ ENGUITA, Mariano. A ambigüidade da docência: entre o profissionalismo e a proletarização. In: Teoria e Educação. Porto Alegre, n. 4, 1991, p. 41 - 61

GIROUX, Henry. Los profesores como intelectuales: hacia una pedagogía crítica del aprendizaje. Barcelona: Paidós, 1990.

GOETZ, Judith; LECOMPTE, Margaret. Etnografía y diseño cualitativo en investigación educativa. Madrid: Morata, 1988.

GÜNTHER, Maria Cecília Camargo. A formação permanente de professores na Rede Municipal de Ensino de Porto Alegre, no período de 1989 a 1999: um estudo a partir de quatro escolas da rede. (Dissertação de Mestrado). Porto Alegre: ESEF/UFRGS, 2000.

HARGREAVES, Andy. Profesorado, cultura y postmodernidad: cambian los tiempos, cambia el profesorado. Madrid: Morata, 1996.

HYPOLITO, Álvaro Moreira. Trabalho docente, classe social e relações de gênero. Campinas: Papirus, 1997.

JAEN, Marta Jiménez. Os docentes e a racionalização do trabalho em educação: elementos para uma crítica da teoria da proletarização dos docentes. In: Teoria e Educação. Porto Alegre, n. 4, 1991, p. 74 - 90.

LISTON, D. P.; ZEICHNER, K. M. Formación del profesorado y condiciones sociales de la escolarización. Madrid: Morata, 1997.

MOLINA NETO, Vicente. La Cultura Docente del Profesorado de Educación Fisica de las escuelas publicas de Porto Alegre. (Tese de Doutorado). Barcelona: Universidad de Barcelona, 1996.

Cultura docente: uma aproximação conceitual para entender o que fazem os professores nas escolas. In: Perfil. Porto Alegre, ano 2, n. 2 , p. $66-74,1998$

Movimento, Porto Alegre, v. 11, n. 1, p.47-70, janeiro/abril de 2005 
Etnografia: uma opção metodológica para alguns problemas de investigação no âmbito da Educação Física. In: MOLINA NETO, Vicente; TRIVIÑOS, Augusto N. S. A Pesquisa Qualitativa na Educação Física. Porto Alegre: Editora da Universidade/Sulina, 1999, p. 107-139.

PÉREZ GÓMEZ, Angel. La cultura escolar en la sociedade neoliberal. Madrid: Morata, 1998.

RODRÍGUEZ GÓMEZ, Gregorio, GARCIA JIMENEZ, Eduardo y GIL FLORES, Javier. Metodologia de la investigación cualitativa. Archidona: Aljibe, 1996.

SECRETARIA MUNICIPAL DE EDUCAÇÃO DE PORTO ALEGRE. $3^{\circ}$ Encontro das Escolas por Ciclos de Formação. In: Cadernos Pedagógicos. Porto Alegre, n. 19, 1999.

II Congresso Municipal de Educação: teses e diretrizes. In: Cadernos Pedagógicos. Porto Alegre, n. 21, mar/2000.

SILVA, Sheila Aparecida P. S. A Pesquisa Qualitativa em Educação Física. In: Revista Paulista de Educação Física. São Paulo, vol. 10, n. 1, p. 87 - 98, jan/1996.

SOUZA, Aparecida Neri de. Sou professor, sim senhor: representações do trabalho docente. Campinas: Papirus, 1996.

WOODS, Peter. La escuela por dentro: la etnografía en la investigación educativa. Barcelona: Paidós, 1995.

Recebido em 10/01/2005 Aprovado em 22/02/2005

Elisandro S. Wittizoreck Rua Vasco Alves Pereira, 520 Bairro N. Sra. de Fátima Guaíba - RS 92500-000 elisandro@tagline.net

Vicente Molina Neto ESEF/UFRGS

Rua Felizardo, 750

Jardim Botânico

Porto Alegre - RS

vicente.neto@ufrgs.br

Movimento, Porto Alegre, v. 11, n. 1, p.47-70, janeiro/abril de 2005 